\title{
Lectura orante comunitaria de la palabra de Dios*
}

\author{
Pedro Trigo, \\ Centro Gumilla, \\ Caracas, Venezuela.
}

\section{La entrega de la Biblia al pueblo, acto de tradición constituyente}

La entrega de la Biblia al pueblo y, sobre todo, de los evangelios es un acto de tradición en el sentido más fuerte de la palabra. Debe ser equiparado a la entrega de la eucaristía. Reviste el mismo carácter solemne y sagrado que se percibe en el relato de Pablo a los corintios (1Co 11, 23).

Ambas entregas acontecen dentro de la comunidad, pero de tal manera que la comunidad se fundamenta sobre ellas cuando se mantiene fiel a ellas. $Y$ es que los evangelios y la eucaristía son obras de la comunidad, pero la trascienden absolutamente. Ambos son misterios y sacramentos de la fe de la comunidad, pero, más profundamente, son acciones del Espíritu y de la palabra de Dios, que es luz, alimento y vida. Su entrega, por lo tanto, no es un acto potestativo de la jerarquía.

Además, los evangelios y la eucaristía pertenecen a la comunidad en su calidad de comunidad creyente, hasta tal punto que la comunión con Jesús es también comunión de unos con olros, y la escucha de la palabra requiere de la escucha mutua (consensus) de los creyentes. Esto no quita que en la comunidad haya carismas particulares, tanto con relación a la palabra como con relación a

- Con este artículo continuamos la reflexión sobre las comunidades. Con anterioridad hemos publicado "Comunidades eclesiales de base", Revisıa Latinoamericana de Teologia 47 (1999) pp.189-205; "Transformaciones que acontccen en las personas populares de las comunidades", Revista Latinoamericana de Teologia 49 (20)(K) pp. 51-67. 
la eucaristía. Por lo que toca a la palabra hay apóstoles, evangelistas, profetas, doctores. animadores y exhortadores. Pero estos dones y ministerios no se dan al margen y por encima de la comunidad, sino que están referidos a su fe, se basan en ella, y a la vez la espolean y cualifican.

Si esto es verdad, tenemos que concluir que nunca faltó del todo en la Iglesia la enlrega de la palabra ni de la eucarislía. Pero eso no significa que siempre y en todo lugar la entrega haya sido todo lo fiel y eficaz que debiera haber sido. La historia muestra que ha habido situaciones en las que casi desapareció, tanto la comunidad viva, como la proclamación de la palabra de Dios y la celebración compartida de la cena del Señor. Esos tres elementos son correlativos entre sí, y a lo largo de la historia han renacido o se han eclipsado juntos.

Por lo que toca a América Latina, al establecerse un sacerdocio postridentino, romanizado, que automáticamente excluía al pueblo como tal, la separación entre el clero y los fieles en los actos de culto se tradujo en la identificación práctica de la Iglesia con el clero. La consecuencia fue la exclusión del pueblo cristiano, que tuvo que establecer por su cuenta su comunitariedad en el catolicismo popular, y el secuestro de la Biblia por parte del clero. Hasta hoy, en América Latina, la Biblia ha sido el libro de la lglesia en el sentido reductor de la institución eclesiástica, de la clerecía. Pero lo más grave es que la clerecía, al no entregarla al pueblo, tampoco la poseyó ( $c f r$. Mt 25,29 ): la Biblia fue sustituida en gran medida por los catecismos, los libros de meditaciones y de casos de conciencia, el derecho canónico y los rituales litúrgicos. Estos incluian, sin duda, frases o episodios biblicos, pero para confirmar sentencias previamente establecidas o para ilustrar una doctrina o una práctica con ejemplos autorizados o para mover a determinadas actitudes y conductas; no como fuente de la revelación.

Sin embargo, gracias al impulso conciliar y a la creativa recepción del concilio Valicano Il en nuestra Iglesia latinoamericana, la Biblia y, sobre todo, los evangelios empiezan a ser ya el libro del pueblo de Dios, especialmente de los pobres. De esta manera se han revitalizado conjuntamente la comunidad cristiana, la recepción orante en comunidad de la palabra de Dios y la celebración viva de la eucaristía. Estos tres aspeclos se retroalimentan entre sí. Y además, como prueba de su autenticidad evangélica, lodo ello acaece entre los pobres o entre los que se solidarizan con ellos, quienes con mucha frecuencia forman comunidad con aquellos en terreno popular.

\section{El aporte de la recepción de la palabra a otras vías de acceso a Jesús}

Para comprender, en positivo, lo que implica esta entrega de la palabra de Dios analicemos, primero, to que ocurre cuando los cristianos no han participado en el proceso descrito. Estos son todavía la mayoría y dan el tono a la situación actual eclesial. 


\subsection{El Jesús santo y el Jesús amigo, con anterioridad a la entrega del evan- gelio}

Comencemos recordando algo fundamental. La palabra de Dios llega hasta nosolros de múltiples modos. Nuestro pueblo la percibe, ante todo, en la vida: Dios habla a través de los acontecimientos, en la voz de la conciencia y en el fondo del corazón. Además, a lo largo de la historia, ha hablado a cada pueblo a través de sus religiones. Al pueblo de Israel lo fue guiando a lo largo de su hisloria, lal como se recoge en la Biblia, a la cual desde nuestra fe reconocemos como palabra de Dios. Pero para nosotros los cristianos, la palabra propia de Dios hecha carne humana es Jesús de Nazaret.

Con esto estamos diciendo que la palabra de Dios es mucho más amplia que la Biblia y que la Biblia es más amplia que Jesús de Nazaret. Pero creemos también que la palabra de Dios, que es Jesús de Nazaret, habla en todas las otras palabras de Dios y las transciende. Transciende incluso los evangelios. Por eso, el pueblo cristiano, aun sin conocer la Biblia, ha escuchado la palabra de Dios, y se ha sentido cristiano, aun sin la lectura directa de los evangelios. Sin embargo, hay que recalcar que la privación de este gran tesoro que es la Biblia y, sobre todo, los evangelios, aunque no interrumpió la relación con Dios, no ha dejado de tener consecuencias importantes.

Veámoslo en la imagen de Jesús de Nazarel, que existe en los ambientes en los que todavía no se ha efectuado la entrega de los evangelios al pueblo. Nos concentramos en este punto no sólo por una razón metodológica, en el sentido de comenzar nuestra investigación por algún punto determinado, sino que obedece sobre todo a una opción teológica, que ahora simplemente enunciamos sin poder justificarla: la entrega —en el sentido fuerte del término- de la Biblia debe comenzar por la entrega de los evangelios, quedando lo demás de la Biblia como referencia, necesaria pero secundaria. Más aún, pensamos que para esta entrega de los evangelios se necesitan varias generaciones, pues, si se quisiera entregar "todo" de una vez, nos tememos que el resultado no será un acto de tradición, sino, más bien, un acto escolar. No será la entrega viva de la palabra de Dios.

Comencemos ya el análisis. Con anterioridad a la recepción del evangelio, Jesús, como palabra personal de Dios, es percibido de dos modos fundamentales, que podemos caracterizar como santo y como amigo.

Para la mayor parte del pueblo - y para otras personas de mentalidad religiosa tradicional no clericalizada-, Jesús es un sanıo, el santo más importante. el santo por antonomasia. Decimos santo en el sentido de que perlenece al mundo divino, a la corte celestial. Su cercanía a Dios concede al santo dos funciones complementarias: por una parte, Dios le da misiones (esporádicas o permanentes) con sus correspondientes poderes; por olra, los scres humanos pueden 
recurrir a él como intercesor ante Dios, ya que, aunque el santo perlenece al mundo de Dios, al no estar tan elevado como Dios, parece más asequible a los que nos vemos tan pequeños y pecadores.

En el caso de Jesús, esta mediación —en ambos sentidos- llega a la perfección porque él es percibido como el Hijo de Dios o simplemente como Dios, pero un Dios que es también un ser humano y, por tanto, como un Dios - paranosotros, que sufre como nosotros y nos conoce y tiene misericordia de nosotros, y que, por supuesto, nos puede salvar con el poder de Dios que posee. Así, pues, Jesús es un ser del mundo de Dios venido a nuestra tierra, no un ser humano propiamente dicho. Se nos presenta como nosolros, pero en el fondo se sabe que no es como nosotros, en definiliva, es Dios. Su historia no es historia propiamente dicha: él ya sabía todo lo que le iba a pasar. El se sometió porque quiso, pues podía haber fulminado a todos sus enemigos, pero eligió padecer y salvarnos con su sufrimiento. Eso es Jesús para la mayor parte del pueblo y, en concreto, para los que comienzan a leer en comunidad los evangelios.

Para otros cristianos, bastantes de ellos de clase media, modernizados en cuanto a su cristianismo, lo mismo que para algunos elementos populares en contacto con religiosas o sacerdotes modernos y sobre tọdo para la mayoría de los jóvenes, que crecen en grupos cristianos no tradicionales, Jesús es el amigo, el amigo con mayúsculas, una persona humana del todo especial. No es un personaje de la historia, sino, ante todo, alguien que vive, que está a mi lado siempre y que me quiere ayudar. "El Maestro está aqui y le llama" (Jn 11, 28). "Soy yo. No tengan miedo" $(J n 6,20)$. Se subraya, entonces, la actualidad de Jesús, su presencia, su cercanía. El ha resucitado; es el vencedor. Si llegamos a sentirlo a nuestro lado, no tenemos por qué temer. El está para protegernos. Pero, además, él nos llama, él quiere contar con nosotros. En este esquema Jesús es el ser humano perfecto. El nos puede llevar hasta Dios, hasta los demás y hasta lo mejor de nosotros mismos. Se subraya la inmediatez de Jesús, su entrega a nuestro servicio y su exigencia a que seamos de los suyos. Pero los contenidos concretos de esta persona llamada Jesús son, en este esquema, bastante volátiles. En general suelen coincidir con las necesidades de cada quien y con el ideal humano que cultiva el grupo.

Comparando los dos esquemas que hemos analizado, en el esquema tradicional, el acceso a Jesús es por vía ritual: los ciclos de navidad y pascua, las misas, las imágenes. La persona llega hasla el sanlo ofreciéndole algo y pidiéndole algún favor. Uno acude con confianza, porque es devolo y se religa al sanlo, que tiene un semblante muy concreto (una imagen, una estampa, una fecha, un lugar). La oblación del oferente, junlo con el hecho de acudir a su santo, simboliza la voluntad que le tiene. A su vez, el santo, al cumplirle al devoto, le expresa su aceptación, con lo cual el devoto queda más comprometido con él. 
En el segundo esquema, el acceso es mediante la oración, que en este caso no son tanto oraciones establecidas, sino la comunicación personalizada de las inquietudes y los anhelos. A diferencia del esquema anterior, en el cual lo que se pide es, de un modo u otro, vida (salud, trabajo, vivienda, comida), lo fundamental que aqui se pide es compañia y protección: que Jesús lo comprenda a uno, que le dé confianza en uno mismo y calor de amistad. En este esquema, la subjetividad es no sólo vehículo de la relación, sino su contenido fundamental.

\subsection{El Jesús que es entregado en el evangelio}

Como se ve, en ninguno de los dos casos Jesús es una persona concreta con unas características concretas y con una propuesta concreta. En ambos se recalca que Jesús es para uno; y hay en ello una inluición certera, ya que Jesús es un ser-para-los-demás. Su modo de existir es la pro-existencia (Sobrino). Como dice el credo: "por nosolros los hombres y por nuestra salvación".

Sin embargo, ante esto hay que recordar lo fundamental: quien vive para nosotros y el amigo incondicional es Jesús de Nazaret y no otro. Quien está en el cielo con Dios o quien está ahí a nuestro lado es esa persona única que es Jesús de Nazaret. Es decir, lo que Dios asumió es esa existencia concreta que vivió Jesús. A quien Dios resucitó fue al torturado y crucificado. Así, pues, Jesús hoy (el Amigo) o Jesús siempre (el Santo) no es otro que el Jesús de la historia (Hb 13,8). La revelación de Dios y de la propia humanidad aconteció en esa irrepetible realidad histórica.

Jesús, pues, salva, pero quien salva es Jesús de Nazaret y no otro. Claro está que Jesús está vivo, no está encadenado a su pasado, condenado a repetir las mismas palabras y acciones. Pero su vida no prosigue como la de Lázaro o como la del hijo de la viuda de Naim o como la de la hija de Jairo. La vida de Jesús terminó o - por mejor decir- terminaron con ella. Los resucilados por Jesús regresaron a este mundo, y su vida continuó abierta e inconclusa, hasta que murieron definitivamenle. Pero no fue así con Jesús. Sus asesinos acabaron para siempre con su vida en este mundo, como lo certificaron los ángeles a las mujeres: "no está aquí" (Mc 16, 6; cfr. Lc 24, 51; Hch 1, 9-11). En ese sen(ido su vida no prosigue, sino que acabó definilivamente. La resurrección que obró Dios en él no es volverle a la vida, sino que es una transformación que equivale a una recreación. Dios lo exaltó, lo llevó a sí, lo sentó a su derecha, lo constituyó Señor de todo lo creado. En la resurrección, Jesús es ya la nueva creación, la nueva humanidad (Ga 6, 15; 2 Co 5,17$)$. Pero, por olra parte, el resucitado es el crucificado. La existencia histórica de Jesús de Nazarel acaba —pero también culmina- en la cruz: en ella se consume y se consuma su vida (Jn 19, 30). Quien vive en Dios ahora como nuestro Señor, es la nueva humanidad de Jesús de Nazaret.

Si éste es el único nombre que puede salvar, entonces, nuestra salvación consiste no sólo en invocarlo como Señor, sino sobre todo en proseguir su 
historia hasla quedar constituidos, nosotros lambién, en mujeres y varones nuevos. Cristo no nos quiere salvar sin nosolros, porque esa salvación no sería humana, pero, por eso mismo, tampoco nos quiere esclavizar a una imitación que nos anula como personas. Por eso, la resurrección de Jesús, o más exactamente su pascua - muerte y resurrección-, significa para nosolros la entrega del Espíritu Santo, el mismo Espíritu de Jesús de Nazarel, para que nosotros podamos realizar en nuesıro tiempo lo equivalente a lo que él realizó en el suyo. El Espíritu no es el Padre, ni el Hijo (aunque es el Espíritu de ambos). Sin el conocimiento de Jesús (incluso de Dios) es posible obedecerlo, dejarse llevar por su impulso, lo cual consiste, aunque ocurra sin tener conciencia de ello, en proseguir la historia de Jesús. Pero para ayudarnos a discernir a su Espiritu dentro de nosotros, distinguiéndolo de otros impulsos, se nos ha entregado en los evangelios la historia viva de Jesús, discernida en la fe por inspiración del mismo Espíritu, que impulsó su historia.

Desde lo dicho $-y$ volviendo al análisis de nuestra situación- hay que afirmar que es correclo considerar a Jesús como santo, alguien que pertenece al mundo de Dios. Pero hay que añadir que quien pertenece a ese mundo es un hombre resucitado, no un ser divino, que se vistió de hombre. Jesús nos sallvó con su pobreza $(2 \operatorname{Co} 8,9)$, es decir, con su humanidad, porque ella es la expresión del compromiso de Dios con nosolros y da la medida de su amor, y en esc sentido - porque Dios es amor- es su revelación plena. Si Dios salvó la vida de Jesús, porque ella realizó su designio (conjuntamente revelador y salvador). es fundamental conocer esa vida para conocer ese designio y ponerlo por obra y ser así resucitados con él. Para capacitarnos para ello se nos dio el Espiritu.

También es correcto considerar a Jesús como al amigo que está a mi lado para ayudarme siempre. Pero hay que añadir que ése, que está realmente presente, no está aquí, no ciertamente en el sentido de eslar a merced mía. Se hace presente desde la trascendencia de Dios. Eso significa que no me salva como yo quiero, sino como quiere Dios, porque ésa es la única salvación, y Jesús fue el que nos reveló ese designio de Dios. Así, pues, la relación actual con el amigo Jesús me lleva a su vida para trascenderla en su seguimiento y, así, salvarme. Pero esa presencia, no lo olvidemos, es en la ausencia. Eso significa que en esa relación actual Jesús "no me cuenta su vida", por asi decirlo, ni a través de la relación con él acaecen nuevas revelaciones. En la aparición más fulminante que se recoge en la historia del cristjanismo, Jesús no declara a Pablo lo que tiene que hacer, sino que lo remite a la comunidad crisliana: "Alli se te dirá lo que tienes que hacer". Pablo recibe la revelación de que aquel a quien él perseguia estaba presente, vivo, en la comunidad cristiana. Pero Jesús no le comunica directamente las tradiciones de la comunidad que se remontan a él. Eso lo recibe por medio de la comunidad.

Así, pues, la relación actual con Jesús es una relación en la fe. No sólo en el sentido en que lo es cualquier relación estrictamente personal, sino $\mathrm{en}$ el sentido 
reduplicativo de que tampoco es perceptible a través del símbolo del cuerpo, ya que él "no está aquí", en este mundo, sino en Dios. Y ahora viene lo fundamental: su cuerpo en la historia son los pobres, es la comunidad, son los evangelios y es - para los que se han encontrado con él en esos tres simbolos- la eucaristía. Nuevamente nos encontramos con la circularidad de los mismos elementos, esta vez considerados como sacramentos de Jesús. No es posible que el amigo Jesús no lleve a cllos, si la persona no se limita a hablarle y pedirle lo que desea, sino que, trascendiendo, se pone a escucharlo. Si lo hace así, al fin conocerá que si es escuchado. Para distinguir dentro de uno mismo la voz del amigo se nos da el Espírilu, que nos irá llevando a los evangelios, a los pobres, a la comunidad y a la eucaristía.

\section{Las comunidades eclesiales de base, lugar de la escucha de la palabra}

\subsection{El ámbito de la comunidad mesiánica}

Hemos dicho antes que en el ambiente cristiano no se da, en general, la recepción de los evangelios y que, sin embargo. es muy conveniente que los evangelios sean proclamados explícitamente para que la relación que de hecho existe con Jesús -como acabamos de ver- dé de sí en plenilud y no sc deforme ni exlravíe.

Hemos dicho también que esta proclamación se está dando en nuestros dias. Más aún, este acto de tradición del evangelio es tan decisivo que constituye un signo de los tiempos: es designio de Dios que hoy se entreguen los evangelios al pueblo latinoamericano. $Y$ el Espíritu de Dios está en esa recepción entusiasta de la palabra de Dios que se proclama. Es también de Dios que esa proclamación acontezca en comunidades eclesiales de base, no obviamente de modo exclusivo, pero sí de una manera especialmente relevante. Veámoslo.

El sujeto de la contemplación del evangelio es el discípulo dispuesto a proseguir su historia. El es el oyente de la palabra. Pero el lugar adecuado para que la escuche es la comunidad eclesial, que se solidariza con los condenados de nuestro mundo. Esto es así porque aquel por el que nos llamamos cristianos sigue siendo el mesías de los pobres y, por tanto, sólo una comunidad que se solidariza con ellos es una comunidad "mesiánica", que eso significa "cristiana". Pero el mesías de los pobres es el condenado, el crucificado: Jesús es el mesías siervo. Por ello, los condenados son su primer sacramento en la historia (Puebla 31-39; Santo Domingo 178-179). La solidaridad con ellos es solidaridad con Jesús y la falta de solidaridad con ellos equivale a no reconocer a Jesús (Mi 25, 45), lo que lleva a no ser reconocidos por él (LC 13, 25-27). Una lglesia que no eslá solidarizada con los pobres no es la comunidad de Jesús. La Biblia es para ella un libro cerrado, y cuando se reúne no celebra la cena del Señor $(1 \mathrm{Co} 11,20)$, a no ser que, consciente de su pecado, esté ante el Señor como Iglesia penitente, 
buscando humildemente su conversión. Entonces, sí puede leer con provecho los evangelios y beber la sangre de la alianza que contiene el perdón de los pecados.

Así, pues, el ámbito donde la palabra se proclama ella misma es la comunidad de los discípulos que, en solidaridad con los pobres, huscan proseguir la historia de Jesús de Nazarel en la fuerza de su Espíritu.

\subsection{Una comunidad de pobres}

Lo más elemental de estas comunidades cristianas, lo más débil también y sin apariencia, lo más pobre en muchos sentidos, pero también lo más medular son las comunidades de pobres que se van hermanando desde su condición compartida de hijas e hijos de Dios. Llamamos comunidades eclesiales de base - sea cual sea el nombre que se den a sí mismas - a esos grupos de pobres que se van llevando mutuamente en su fe, que se aman como hermanos y que se animan recíprocamente con la esperanza que Dios les da, y así son fermento de vida digna y compartida en sus ambientes. Pues bien, en ellos, sobre todo, la palabra de Dios que reluce en los evangelios se proclama con más creatividad y fecundidad. Esta afirmación expresa un acontecimiento de envergadura histórica, un acontecimiento que nos hace vivir, que nos sorprende cada día, que nos llena de agradecimiento, en medio de su desnuda sencillez, incluso de su precariedad.

Pero si este acontecimiento nos sorprende es porque pensamos según los criterios del orden establecido y no tenemos la mentalidad de Dios. Desde ella, tal como se nos revela en los evangelios, es claro que el evangelio es para los pobres (Lc 4, 18; 7, 22), porque de ellos es el reino de Dios (Lc 6, 20). Por eso, Jesús los proclama dichosos. Claro está que los pobres pueden no aceptar ese reino que Dios les entrega, pero, de todos modos, el favor de Dios, su predilección y su cercanía no deja de tener consecuencias para el pobre que escucha los evangelios. Los evangelios siempre exigen conversión y contienen una Irascendencia que nunca desaparece; pero los pobres, a la vez que esa exigencia y esa distancia absolutas, sienten también una especial cercanía y una como connaturalidad cuando escuchan los evangelios, que es el efecto en ellos de esa condescendencia de Dios.

En un análisis antropológico podríamos pensar que el pobre necesita pedir porque no liene cómo conseguir lo que no tiene, que necesita buscar la vida porque carece de ella y con frecuencia se le niega, y que necesita llamar a la puerta porque precisa ayuda de un modo perentorio. Parece que el pobre sería quien está más preparado a abrir el corazón a las buenas noticias. Sin embargo, tanta desesperanza acumulada le puede llevar también a no confiar en nada ni en nadie y, por tanto, a no pedir ni llamar, a no buscar ni dar crédito. Los pobres pueden, ciertamente, cerrarse al evangelio. El que los pobres se abran a él será siempre un acontecimiento: un encuentro entre la gracia de Dios, que se ofrece en Jesús como salvación, y la libertad del que, reconociéndose necesitado de esa salvación, recibe la semilla de la palabra con todo su corazón. 
Este acontecimiento es imprevisible, aun sabiendo que el evangelio se dirige a los pobres. Aunque nunca determina la voluntad, sí es capaz de moverla hacia él. Pero el evangelio, al ser revelación histórica, entra por el oído ( $\mathrm{Rm} 10$. 14.17). Es, por ello, imprescindible la existencia de evangelizadores que entreguen al pueblo este evangelio, que por voluntad de Dios les pertenece.

Por aquí comenzó en América Latina la novedad. Tras el concilio comenzaron a surgir agentes pastorales que, habiendo descubierto ellos mismos, de un modo renovado, la palabra de Dios, comenzaron a entregarla al pueblo mediante la lectura orante comunitaria. Se llegó a la vez al redescubrimiento de la estructura comunitaria de la lglesia, de la primacía de la palabra de Dios como fuente de la revelación y del privilegio de los pobres en la Iglesia, y se llegó al discernimiento de los signos de los tiempos como modo de descubrir la voluntad salvadora de Dios. Pronto se vio que lodos estos redescubrimienlos formaban una matriz. De ahí salieron, entre otras novedades históricas, las comunidades eclesiales de base.

En ellas están los destinatarios por excelencia del evangelio: los pobres. Pero es que, además, están en ella como discípulos: como quienes se reúnen para oír y seguir. Son, pues, ya, en cierto modo, pobres con Espíritu. Y se reúnen porque son convocados. Es Dios el que los atrae a Jesús al reunirlos en la comunidad que lleva su nombre: la comunidad de los cristianos, la Iglesia, la misma comunidad —en continuación histórica- de los discípulos de Jesús de Nazaret.

Estos pobres tienen la fragilidad y los pecados de cualquier ser humano, lodo lo cual está agravado por su situación infrahumana, y por el desprecio y la opresión que pesan sobre ellos, que inducen a la deshumanización. Pero también en ellos hay Espíritu, porque viven no teniendo cómo vivir, porque, además, viven de fe y también porque vienen a recibir el evangelio de Jesús y a hacerse sus discípulos. Es obvio que estas personas están en condiciones excepcionales para recibir la revelación de Jesús en los evangelios desde esa palabra en la que hoy él nos habla para nuestra salvación.

La práctica confirma que esto es así. En la lectura del evangelio, en las comunidades de base, se muestra que Dios revela su misterio - la salvación que realiza en Jesús- a la gente sencilla y que lo oculta a los que se tienen por expertos en las cosas divinas.

\section{Lectura orante comunitaria de la palabra de Dios: un método}

Esta revelación se da muchas veces al margen $\longrightarrow$ incluso en contra- de la letra de los evangelios. Aun sin entender claramente lo que leen, captan el evangelio de Dios en ellos. Sin embargo, también es cierto que la predilección de Dios no significa que los pobres son infalibles. El no entender puede ser también ocasión de que se manifiesten otros espíritus que no son el de Jesús. De ahí la importancia de que se entienda la palabra. El Espíritu es el de la palabra. No 
se la puede poner en práctica, aunque se desee, si no se la comprende. Si se leyera el evangelio en su lengua original, por ejemplo, o si los personajes que salen en sus páginas hablaran en su propia lengua, la comunidad no podría responder, porque no entendería lo que Dios quiere decirle.

\subsection{Dificultades}

Las comunidades que inlentan escuchar seriamente la palabra de Dios con mucha frecuencia encuentran dificultades. Es posible que ni siquiera entiendan algunos términos, como, por ejemplo, sinagoga, fariseo, tribulo, demonio, endemoniado, templo, impuro, impureza, mesías, magos, saduceo, publicano, samarilano... A veces, aun comprendiendo los términos, no perciben el alcance de lo que se propone en el relalo: curar en sábado, sentarse a la mesa con pecadores públicos y pobres, hablar con una mujer, bendecir a los niños, exigencia de dejar la familia para seguir a Jesús, incompatibilidad entre Dios y el dinero...

La dificultad está en que los evangelios fueron escritos en otro tiempo y en otra cultura, y además, en una cultura muy integrada que, por tanto, podía dar muchisimas cosas por sobreentendidas, ya que eran compartidas por los que escribían y por los posibles destinatarios. Además, las siluaciones de las comunidades que están a la base de los evangelios no son las mismas que las de la historia de Jesús. Por eso, los evangelios efectúan ya una iransposición de registros - lo mismo que tenemos que hacer hoy-, de modo que los evangelios son modelos de lo que nos toca hacer a nosotros. Sin embargo, esa transposición era bastante homogénea dentro de la heterogeneidad, ya que la cuenca del Mediterráneo oriental, siendo un mosaico muy abigarrado de culturas, tenía elementos comunes, una misma matriz de la que cada cultura era una variante.

Según esto, en la lectura orante de los evangelios no se puede tratar de una mera aplicación de los evangelios a nuestra situación, sino de prolongar hoy el impulso que llevó a las comunidades cristianas a escribirlos, de modo que, de alguna manera, los reescribamos para proseguir, como ellos, la misma historia de Jesús. Hay que reescribir los evangelios, pero no al margen de ellos o por encima de ellos - como si los domináramos-, sino con fidelidad, sabiendo que la fidelidad verdadera es creativa, pues es histórica, y tiene por objetivo abrir la hisloria hacia la parusía.

Todo esto plantea un problema: la distancia entre los evangelios y nosotros exige ser mediada. Lo contrario, pretender que se da sin más la inmediatez, conduce al fundamentalismo o a la arbilrariedad. El Espíritu es el de la palabra y la palabra se hizo came, es decir, historia. Es cierto que la palabra ha sido resucitada por Dios y habla en los evangelios cuando se los escucha discipularmente. Es cierto que el Espíritu es el intérprete adecuado: el mismo que inspiró a los autores inspira hoy a los receptores. Es cierto que ese Espíritu está en la comunidad cristiana de base. Pero, insistimos, el Espiritu interpreta la palabra y 
la palabra es histórica, y por eso debe ser entendida para que pueda ser interpretada. Ser entendida no es lo mismo que ser interpretada. Se puede entender cada elemento de un relalo sin comprender nada intemamente. Pero, icómo comprender el mensaje si no se lo entiende? María preguntó porque dio fe al anuncio del ángel. Como tenía la voluntad de cumplir el designio de Dios, preguntó qué significaba el saludo del ángel y de qué manera iba a realizar Dios lo que le proponia.

Ahora bien, la necesidad de la mediación no implica que la Biblia sea coto de expertos. La mayoría de ellos, en tiempo de Jesús, tenian muchos saberes, pero ese saber no les sirvió para percibir la revelación de Dios en Jesús. Al contrario, el modo concrelo de su saber les impidió reconocerla. - $\mathrm{Y}$ en cambio el pueblo, "esos maldilos que no conocen la ley", fueron capaces de sopesar "que nadie ha hablado como este hombre"-. Así, pues, hay un mínimo indispensable de saber (el que no tenía el intendente de Candace y se lo proporcionó Felipe). Pero, traspuesto ese umbral, no hay ventaja por parte del que sabe más.

Eso significa que la mediación exegélica debe ser lo más parca posible. Debe mantener siempre su condición preliminar. El agente pastoral nunca debe convertir en clase lo que tiene que mantenerse, también para él, en escucha amorosa, agradecida, reverente y obediente de la palabra.

El objetivo de esta mediación no puede ser suprimir la distancia. Esa impresión de inmediatez sería ilusoria, un verdadero cortocircuito que destruiría la realidad del texto. Se trata de acceder a él, salvando, en cierto modo, la distancia. Esto no puede llevarse a cabo reconstruyendo los contexios en toda su complejidad. Resultaría una clase y se acabaría esfumando la palabra de Dios en lo que tiene de voz, de proclamación actual.

Además, hay textos bíblicos que, de buenas a primeras, son inaccesibles para la comprensión. Para la comunidad son como lexlos cifrados. Mientras la comunidad no domine las claves, no puede contemplarlos, ni orar con ellos. Estas claves son saberes, digamos científicos, que hay que aprender por medio de cursos o con otras lecturas auxiliares. Pero hay otros textos en la Biblia que, con algunas breves explicaciones preliminares (bien sean terminológicas, bien sean de contextualización), resultan realmente accesibles.

Esta accesibilidad se puede deber a diversos motivos. Uno - bien frecuente y relevante para las comunidades cristianas populares de América Latina- puede ser la homología estructural entre la situación que se presenta en el texto y la situación de la comunidad. Esta percibe la distancia, pero también la semejanzá. Son situaciones distintas, pero la correlación de los agentes sociales ofrece tal semejanza que basta para que los que escuchan se hagan cargo de aquello a lo cual apunta la palabra de Dios. Otra razón de accesibilidad la constituyen los elementos transculturales, inherentes al pasaje que se proclama. Esos elementos transculturales se dan en una determinada trama cultural, pero existen. Por eso, personas de culturas diversas pueden comunicarse entre sí y -a pesar de mu- 
chos posibles equívocos por la diversidad de códigos culturales- pueden entenderse en muchos aspectos fundamentales.

Hay, pues, mensajes culturales casi inaccesibles para personas de otra cultura, pero otros mensajes están bastante abiertos a la comprensión. En la Biblia puede ser el caso del Levítico o los libros apocalípticos o las disquisiciones rabínicas de las cartas de Pablo, por un lado. y el de los evangelios sinóplicos, por el olro. Muchas narraciones evangélicas y no pocas sentencias de Jesús son directamente asequibles para el pueblo.

Es cierto que un estudio exegélico aportará muchos dalos a los cuales no se llega en una lectura orante de una comunidad cristiana. Pero no lo es menos que estos cristianos empobrecidos también son capaces de descubrir aspectos bien medulares, que no son suficientemente esclarecidos y valorados por la comunidad científica.

En resumen, hemos mostrado la necesidad de una mediación exegélica para que la comunidad comprenda los términos y para que se haga cargo del alcance de lo que se propone, cuando el texio presupone unas claves cullurales, que no son accesibles para ella. Hemos insistido en que este trabajo debe ser lo más sobrio posible, de tal modo que, por su duración, resulte realmente preliminar. Esta mediación puede establecerse por tres vías: bien por la declaración de una persona, que lo pueda hacer competentemente, bien por una edición bíblica que contenga las notas pertinentes, bien por una guía auxiliar, que se entregue para cada tema, teniendo en cuenta muy concretamente el nivel de conocimienlos de la comunidad.

\subsection{La contemplación}

Una vez comprendido el código del texto, iestá concluida ya la escucha adecuada de la palabra? En nuestra experiencia, ciertamente no. Más bien, es entonces, precisamente, cuando comienza la escucha propiamente dicha: la contemplación de la escena, si se trata de una narración, o el darle vueltas en el corazón, si el texto es una sentencia o un discurso. Esto es asi porque la comunidad se ha reunido para recibir como discípula la palabra de Dios; para recibirla con todo el corazón, con toda el alma, con toda la mente; para recibirla en orden a seguirla; más aún, para ser Iransformada por ella. La comunidad se ha reunido, porque ha creído que Jesús es la luz del mundo. Está ahí porque quiere escucharlo y seguirlo para no caminar en linieblas. Ella sabe que, si camina tras él, tendrá la luz de la vida (Jn 8, 12). Las diversas palabras de la palabra de Dios son semillas para la comunidad. La comunidad cree que en ellas hay poder germinador y transformador. Crecen en los corazones por sí mismas, sin que la persona sepa cómo (Mc 4, 27-29). Por eso, la comunidad ora como María: "hágase en mí según lu palabra" (Lc 1,38).

La primera actitud que la comunidad fomenta en este momento, el clima en los encuentros con la palabra, es el deseo de escuchar to que Dios le quiera 
decir. La comunidad en este momento no saca lodavía nada de sí misma: no es el momento de intercambiar experiencias. Es el momento de abrirse. Es la actitud del siervo: "cada mañana despierta mi oído para escuchar como los iniciados; el Señor Yahvéh me ha abierto el oído" (ls 50, 4-5). Dios nos liene que abrir el oído. Si no, ¿cómo el ser humano será capaz de percibir su palabra y de reconocerla? ¿Será el ser humano capaz de Dios? El que nos habla es el que nos afina el oído para que podamos recibir su mensaje. Pero no basta con la acción capacitante de Dios. Es preciso que el ser humano acepte la palabra con un corazón abierto, generoso y enlero (Mc 4, 3-6). Es preciso que nuestra libertad consienta en esta acción de la palabra en nosotros. Por eso, la comunidad recuerda la advertencia del salmo: "si escuchan hoy su voz, no endurezcan sus corazones" (Sal 95, 7-8; cfr. Hb 3, 7-4,11; 1Co 10, 1-13).

Con estas disposiciones, reavivadas en cada encuentro, se entra al texto. Si es una escena, se trata de entrar en ella: ver, oír y palpar (1Jn 1, 1). Para exprimirla, hay que ir, casi se puede decir, palabra por palabra. Ante todo, captar la situación de los personajes en la escena antes de que se desarrolle la acción. Seguidamente, hay que centrarse en lo que sucede: el desarrollo de la acción tal como aparece en el evangelio. Luego, la reacción de los diversos personajes. La acción la puede iniciar alguien que se acerca a Jesús (un menesteroso que le suplica, los enemigos que lo ponen a prueba...), y Jesús reacciona. $O$ es Jesús el que toma la inicialiva y son los demás los que responden de diverso modo. Hay un encuentro $o$ un desencuentro. $Y$ de él dimana una transformación salvadora o un endurecimiento. Siguiendo el pulso al relato se llega a percibir la secuencia, la hilazón, lo que hay en la escena de acontecimiento, de revelación, de salvación.

Una escena habla cuando se va a ella con una pregunta. Por eso, desentrañar una narración es preguntar y seguir preguntando. Una escena evangélica es inexhaurible: cuanto más se la pregunta, más da de sí, más clara se muestra, más se hace presente, más cobra vida anle nuestros ojos. Las preguntas dependen, en gran medida, de nuestro interés. Cuando a alguien le cuentan algo que le imporla, acosa con preguntas al que le informa, y él mismo se pregunta muchas más cosas y trata de responderse con la experiencia que tiene de las personas implicadas en la escena y con su propia experiencia de vida. No son preguntas de pura curiosidad. Son preguntas motivadas, porque se capta que lo que lo que se narra tiene que ver con mi vida, y yo quiero hacerme cargo de ello. No son preguntas capciosas. ni extemporáneas. Están encaminadas tan sólo a que sea la propia escena la que hable, la que dé de sí. No hay ningún propósito de forzar la escena. Por el contrario, lo que se quiere es impregnarse realmente de ella, recibirla lo más enteramente posible y abrirse a ella con toda la vida y lo más hondamente de que uno es capaz, de modo que uno camine con ella.

Eso lo hacemos ante una noticia que para nosotros es importante, sin necesidad de tener una cultura especial, aunque es cierto que cuanto más humanos 
seamos y más dependa de ello nuestra vida, mayor interés mostraremos y más vitalmente nos situaremos ante ella. Lo mismo podemos hacer con los evangelios, si estamos persuadidos de que ellos son para nosotros luz para nuestra vida. Por eso, hernos insistido tanto en esta condición, y por eso creemos que los pobres, que necesitan la vida, están en condiciones óplimas para escuchar el evangelio, y por eso pensamos - a la inversa- que quien ya está fundamentalmente satisfecho, porque piensa que ya es dueño de la vida —es rico o eslá asegurado— o porque piensa que ya tiene la llave del conocimiento -es experto en las cosas de Dios- no puede escuchar con lodo el corazón la proclamación de la palabra.

Con esto hemos constatado la interacción entre el grado de apertura de cada quien y la recepción de la palabra. La palabra puede irrumpir soberanamente y derribarnos, como hizo con Pablo de Tarso, (Hch 9, 3-6). Pero lo normal es que, según la propia apertura, preguntaremos más o menos, preguntaremos para quedar bien o por mera curiosidad o porque buscamos y necesilamos, preguntaremos unas cosas u otras, y en esa misma medida se nos abrirá la escena bíblica, aunque superabundantemente. Por eso, sucede también que podemos leer un mismo pasaje en distintas ocasiones vitales y nos dirá cosas diversas. En una ocasión casi no nos dirá nada, y en otras puede ser que nos deslumbre.

Es radicalmente distinto escuchar y preguntar desde la búsqueda de vida y salvación, desde la menesterosidad y el deseo, desde la intima pobreza, desde la entrega de sí mismo, es decir, preguntar desde la vida que se vive y desde el fondo de la persona, que preguntar desde lo que ya se sabe para saber más. Sólo en el primer caso estamos ante la lectura orante de la palabra. Desde la vida se escucha la palabra para vivir desde ella, para encontrar vida, para salvarnos.

Pero todos tenemos nuestra vida y, por tanto, todos tenemos capacidad de preguntar desde ella. El vivir la vida y la determinación de vivirla desde Dios nos capacila para pregunlar a la Biblia (sobre todo a los evangelios, que "son su corazón", como dice Juan Pablo II) de manera que la escena que leemos orantemente dé de sí. Todos tenemos esta capacidad.

Por otra parte, si la reunión de la comunidad es controlada por el experto, si sólo él piensa que sabe lo suficiente para preguntar al texto, entonces, los demás no preguntarán al texto, sino al experto. $Y$ el texto ya no les hablará a ellos y ellos no se atreverán a responder. Y si responden, su actituơ no será la de decir con libertad lo que les dice el texto, sino que responderán volviéndose al experto para que él confirme si acertaron o no. El interés se habrá desviado hacia el saber más, y de esto la llave la liene el experto.

Para no caer en esa desviación es importante distinguir entre la fase preliminar, que mira a la comprensión del texto, y el centro del encuentro, que es la contemplación orante a partir de la vida del pueblo — vida que le es negada-y de su fe -que le capacita para vivir a pesar de todo. En esla fase lo fundamental es mantener el clima y la dirección. Si éstos se dan, la escena se contempla entre 
todos, cada aporte saca un nuevo matiz, hasta que la escena ya dio de sí según la luz de la vida que posee el grupo. Es el momento de pasar a la fase siguienle.

\subsection{Los frutos de la contemplación}

Después de contemplar viene el reflectir. La mayor parte del liempo lo debe llevar la contemplación, de modo que por connaturalidad se nos vaya pegando la mentalidad de Jesús, su sentir profundo, sus actiludes, su modo de relacionarse... Ese es el fruto indireclo de la conlemplación, un fruto que madura muy lentamente y como sin querer, ya que lo que estamos haciendo es contemplar a Jesús. No cstá nuestra altención puesla en nosotros mismos, sino toda ella concentrada en él. No nos buscamos a nosolros mismos. En ese momenlo no buscamos ni siquicra nuesIra salvación. Estamos fuera de nosolros mismos: viendo, palpando, gusitando...

Sólo después de habernos llenado de su presencia nos preguntamos por la actualidad de esa palabra para nosutros. Esa palabra histórica, ese episodio de Jesús de Nazaret se proclama hoy a nosotros. ¿Qué me ha estado diciendo a mí en concreto? Cada quien mira para adentro y escucha los ecos de esa escena, aquello que quedó resonando dentro de su corazón. Todo vuelve a pasar, no ya en detalle, sino en lo esencial, y dirigido a la siluación de cada uno. Dios no echa discursos. La palabra toca delicadamente fibras profundas y sensibles. Va al centro de lo que está en cuestión, de lo que exige conversión o propone una nueva aventura, una salida del mundo habitual. A veces se vuelve pura alegría: es la confirmación esperada de algo importante. Con frecuencia, de buenas a primeras, causa dolor porque pone el dedo en la llaga, pero es para curarla, y al fin lo deja a uno en paz y contento. Hay días en que le habla a uno por la voz de alguna hermana o hermano, quienes expresan lo que les habló a ellos.

En general se puede decir que, cuanto más honda y menos medializada fue la contemplación, más garantías hay de que sea en verdad la palabra la que habla a cada quien. Indicios internos son el que sean palabras de peso, palabras que hacen al caso, palabras que cuesla decir y que iransforman, palabras en las que está implicado vilalmente el sujeto que las dice y que no son pura redundancia de lo que es y lleva a cabo, sino que lo empujan más allá de sí mismo. Respecto del grupo como tal, el indicio más lehaciente de que realmente hay escucha y respuesta es que las reuniones no son redundantes, cosa que ocurre cuando cada quien dice lo que se le ocurre, lo que tiene dentro.

Si hay transcendencia, a medida que el gnupo avanza escucha más y responde más a fondo. El resultado es que los encuentros son verdaderos acontecimientos para los participantes y que edifican a la comunidad. Esta mutua escucha sagrada es fuente primordial de fraternidad evangélica. 